\title{
Sterol Carrier Protein X (SCPX) Is a Peroxisomal Branched-Chain $\beta$-Ketothiolase Specifically Reacting with 3-Oxo-pristanoyl-CoA: A New, Unique Role for SCPx in Branched-Chain Fatty Acid Metabolism in Peroxisomes
}

\author{
R. J . A. Wanders, ${ }^{*} \dagger^{1}$ S. Denis,* F. Wouters, $\neq$ K. W. A. Wirtz, $\ddagger$ and U. Seedorf§ \\ *Department of Clinical Chemistry and †Department of Pediatrics, Emma Children's Hospital, \\ Academic Medical Centre, University of Amsterdam, P.O. Box 22700, 1100 DE Amsterdam, The Netherlands; \\ $\ddagger$ Centre for Biomembranes and Lipid Enzymology, Utrecht University, P.O. Box 80054, Utrecht, The Netherlands; \\ §Institut für Arterioskleroseforschung, Universität Münster, 48149 Münster, Germany
}

Received J une 14, 1997

One of the most important functions of peroxisomes, at least in humans, is the $\beta$-oxidation of a range of different fatty acids and fatty acid derivatives. Recent studies have shown that the enzymatic machinery required for the $\beta$-oxidations of these substrates, may be much more complex as originally thought. We now report that the conventional peroxisomal thiolase which has sofar been thought to catalyze the thiolytic cleavage of the 3-oxoacyl-CoA esters of all fatty acids oxidized in peroxisomes, shows poor reactivity towards the 3-oxoacyl-CoA esters of 2-methyl branchedchain fatty acids such as pristanic acid. Our data further show, that SCPX, a $58 \mathrm{kDa}$ protein with both thiolase and sterol carrier protein activity but unknown function sofar, readily reacts with 3-oxopristanoylCoA. Taken together, our data show that SCPX plays a central role in branched chain fatty acid $\beta$-oxidation in peroxisomes. This finding has major implications not only for the functional organization of the peroxisomal $\beta$-oxidation system but also for studies dealing with the resolution of the underlying defect in patients with some defect in peroxisomal $\beta$-oxidation. () 1997 Academic Press

Sterol carrier protein 2 (SCP2), alternatively called non-specific lipid transfer protein (nsLTP) is a small basic protein assumed to participate in the intracelluIar transport of sterols and other lipids [1]. Indeed, SCP2 has been found to promote the exchange of various lipids and sterols between membranes, stimulates the enzymatic conversion of 7-dehydrocholesterol to

\footnotetext{
${ }^{1}$ Correspondence: Fax: 0031.20.696 2596. E-mail: wanders@ amc.uva.nl.
}

cholesterol in microsomes and also the acyltransferase mediated esterification of intracellular cholesterol [1]. Moreover, in steroid hormone producing cells SCP 2 is thought to facilitate the transport of cholesterol to mitochondria, where the first committed step in the formation of pregnenolone takes place [2-5].

SCP 2 has been purified from a variety of sources and its structure appears to be highly conserved across mammalian species [1]. SCP2 is synthesized on free polysomes as a larger precursor polypeptide of $14.5 \mathrm{kDa}[6,7]$ with a Type 1 Peroxisome Targeting Sequence (PTS1) at its carboxy-terminus [8-13]. This ensures uptake of pre-SCP2 into peroxisomes followed by processing to the mature 13.2 kDa SCP2 inside peroxisomes which explains its predominant if not exclusive localization in peroxisomes [14-17]. Several lines of evidence pointed to the existence of a SCP2-related protein. Firstly, the antibody raised against SCP 2 was found to crossreact with a higher molecular mass protein of $58 \mathrm{kDa}[6,7,14-16]$. I $\mathrm{n}$ addition, the livers of all mammalian species studied contain SCP2-related transcripts encoding for larger proteins that were found to be identical to pre-SCP2 at their C-terminal domains [8-13; 18-21]. It is now clear that the $58 \mathrm{kDa}$ protein called SCPx [1] and the $14.5 \mathrm{kDa}$ pre-SCP2 are the products of different mRNAs produced from the same gene which has two promoters [22]. Interestingly, significant sequence homology was found between the first 400 amino acid residues of SCPx and both mitochondrial and peroxisomal 3-oxoacyl-CoA thiolase[11,18,23]. Direct activity measurements showed that SCPx, indeed, possesses 3-oxoacyl-CoA thiolase activity next to its intrinsic sterol carrier protein and lipid transfer activity [24]. The substrate specificity of SCPx, however, was found not to differ much from that of the 
conventional peroxisomal thiolase characterized by Hashimoto and coworkers [25].

Until recently it was believed that one set of peroxisomal $\beta$-oxidation enzymes would be responsible for the peroxisomal $\beta$-oxidation of the large variety of fatty acids and fatty acid derivatives known to be $\beta$-oxidized in peroxisomes. Recent studies, however, have shed new light on the pathway of fatty acid oxidation in peroxisomes and have shown that at least the first step in the $\beta$-oxidation of straight-chain and 2-methyl branched-chain fatty acids is catalyzed by distinct acylCoA oxidases (see [26] for review). Elaborating on this work we now provide strong evidence against the concept of a single peroxisomal thiolase catalyzing the thiolytic cleavage of all kinds of different 3-ketoacyl-CoA esters in peroxisomes. We show that 3-ketoacyl-CoA esters of 2-methyl branched-chain fatty acids can not be handled by the conventional, clofibrate-inducible thiolase [25] but instead by SCPx (SCP2/3-oxoacyl-CoA thiolase). Theseresults provide further evidencefor the existence of two distinct $\beta$-oxidation systems in peroxisomes.

\section{MATERIALS AND METHODS}

Preparation of peroxisomes from control and di-(2-ethylhexyl) phthalate (DEHP) treated rats. Male Wistar rats (200-250 g) were fed a standard laboratory diet with or without 1\% (w/v) DEHP for 9 days as described before [27]. Livers were subsequently removed, finely minced and homogenized using a standard isolation medium containing $250 \mathrm{mM}$ sucrose, $2 \mathrm{mM}$ EDTA and $5 \mathrm{mM}$ Mops- $\mathrm{NaOH}$ (final pH 7.4). The resulting homogenate was subjected to differential centrifugation to prepare a light-mitochondrial fraction which was then applied to a Nycodenz density gradient prepared as described elsewhere [28]. After centrifugation the gradient was unloaded and marker enzyme activities (catalase for peroxisomes, glutamate dehydrogenase for mitochondria, esterase for microsomes) were measured in the fractions obtained. The fractions highest in catalase activity contain peroxisomes of high purity (>98\%) [27] and were used as such.

Enzyme activity measurements. Catalase was measured spectrophotometrically using a newly devel oped method based on the peroxidative action of catalase at high ethanol concentrations. The assay medium contained the following standard components: $100 \mathrm{mM}$ potassium phosphate $(\mathrm{pH} 7.4), 0.05 \%(\mathrm{w} / \mathrm{v})$ Triton X-100, 10\% (v/v) ethanol, $10 \mathrm{mM}$ pyrazol, $1 \mathrm{mM}$ NAD and $1 \mathrm{U} / \mathrm{ml}$ aldehyde dehydrogenase. Reactions were started by the addition of $5 \mathrm{mM} \mathrm{H}_{2} \mathrm{O}_{2}$ and the absorbance at $340 \mathrm{~nm}$ was followed in time.

Acyl-CoA oxidaseactivities were measured as described before [29] using palmitoyl-CoA and pristanoyl-CoA as substrates and the homovanillic acid/peroxidase system to monitor formation of $\mathrm{H}_{2} \mathrm{O}_{2}$. See [29] for full details.

Thiolase activity measurements were performed as described below using 3-oxopalmitoyl-CoA and 3-oxopristanoyl-CoA as substrates. The reaction mixture contained the following standard components: $100 \mathrm{mM}$ Tris/HCl pH 8.0, 70 $\mu \mathrm{M}$ CoASH, $25 \mu \mathrm{M}$ 3-oxopalmitoyl-CoA or $10 \mu \mathrm{M}$ 3-oxopristanoyl-CoA (unless otherwise indicated) with or without $4 \mu \mathrm{M}$ defatted bovine serum albumin (Sigma Co., St. Louis, USA). Reactions were started by the addition of enzyme preparation (purified peroxisomes, purified peroxisomal thiolase I [25] or purified SCPx [24]). Appropriate dilutions were made in 20 $\mathrm{mM}$ Mops/50\%(v/v)glycerol (final pH 7.4). Incubation volume: $100 \mu \mathrm{l}$. Reactions were terminated at appropriate time points (usually 5 min.) by the addition of $10 \mu \mathrm{l}$ of a $50 \mathrm{mM} \mathrm{N}$-ethylmaleimide (NEM) solution followed by acetonitrile (final concentration: $40 \%(\mathrm{v} / \mathrm{v})$. After centrifugation at $4^{\circ} \mathrm{C}$ the supernatant was applied to a reverse-phase C18-column (Supelcosil SPLC-18-DB, $250 \mathrm{~mm} \times 10 \mathrm{~mm}$, Supelco). Resolution between the different CoA-esters was achieved by elution with a gradient of acetonitrile $(40 \rightarrow 58 \%(\mathrm{v} / \mathrm{v}))$ in $16.9 \mathrm{mM}$ sodium phosphate buffer ( $\mathrm{pH} \mathrm{6.9)}$ at a flow rate of $3 \mathrm{ml} / \mathrm{min}$. This procedure allows good resolution between the substrates (3-oxopalmitoyl-CoA and 3-oxopristanoyl-CoA) and the respective products (myristoyl$\mathrm{CoA}$ and 4,8,12-trimethyltridecanoyl-CoA) of the thiolase reactions. Absorbance at $254 \mathrm{~nm}$ was measured continuously.

Synthesis and purification of 3-oxopalmitoyl-CoA and 3-oxopristanoyl-CoA. 3-Oxopalmitoyl-COA was synthesized enzymatically from palmitoyl-CoA (Sigma, St. Louis, USA) using acyl-CoA oxidase, crotonase and 3-hydroxy-acyl-CoA dehydrogenase which are all commercially available (Sigma, St. Louis, USA). Apart from the enzymes the reaction medium had the following composition: $50 \mathrm{mM}$ Tris/ $\mathrm{HCl}, 100$ $\mu \mathrm{M}$ FAD, $5 \mathrm{mM}$ pyruvate, $1 \mathrm{mM}$ NAD, $2.5 \mathrm{U} / \mathrm{ml}$ lactate dehydrogenase, $150 \mathrm{mM} \mathrm{KCl}$. Final pH 8.5. 3-Oxopristanoyl-CoA was also synthesized enzymatically. Pristanoyl-CoA was used as starting substrate as prepared from pristanic acid following the method of Rasmussen et al [30]. A purified peroxisomal fraction $(0.25 \mathrm{mg} / \mathrm{ml})$ was used to convert pristanoyl-CoA into 3-oxopristanoyl-CoA. The 3-oxoacyl-CoA esters were purified by HPLC using the chromatographic conditions described above and stored at $-20^{\circ} \mathrm{C}$ in a buffer containing $20 \mathrm{mM}$ MES, final $\mathrm{pH} 6.0$ in which they were found to be stable for extended periods of time.

Purification of the peroxisome proliferator-inducible thiolase [25] and SCPx [24]. The peroxisome proliferator-inducible thiolase was purified to apparent homogeneity on SDS/PAGE from clofibratetreated rats using the procedure described by Hashimoto and coworkers [25]. Rat liver 58kDa SCPx (SCP2/3-oxoacyl-CoA thiolase) was prepared by expressing the full-length CDNA coding for the entire SCPx (547 amino acids) in E. Coli followed by purification of the protein (see [24] for full details).

\section{RESULTS}

We and others recently discovered that straightchain fatty acyl-CoA esters like palmitoyl-CoA and 2methyl branched-chain acyl-CoA esters like pristanoylCoA are oxidized by two distinct peroxisomal acyl-CoA oxidases. The first indication for the existence of two distinct oxidases came from experiments in which we studied the effect of clofibrate, a known inducer of peroxisomes [26], on the peroxisomal oxidase activities with palmitoyl-CoA and pristanoyl-CoA as substrates in rat liver and kidney [29]. Palmitoyl-CoA oxidase activity was found to be stimulated manyfold by cl ofibrate whereas pristanoyl-CoA oxidase activity remained unchanged [29]. These studies were soon followed by the identification of rat pristanoyl-CoA oxidase as a distinct enzyme following its purification and subsequent cDNA cloning (see [26] for review).

We have now used the same approach to resolve whether the 3-oxoacyl-CoA esters of straight-chain and branched-chain fatty acids are handled by the conventional peroxisome proliferator-inducible peroxisomal thiolase as believed until now or not. To this end peroxisomes were isolated from livers of control and DEHPtreated rats using density-gradient centrifugation on Nycodenz which procedure results in peroxisomes of 
TABLE 1

Activity Measurements of 3-Oxopristanoyl-CoA Thiolase, 3-OxopalmitoylCoA Thiolase, and Other Enzymes in Peroxisomes from Normal-Fed and Diethylhexylphthalate (DEHP)-Fed Rats

\begin{tabular}{|c|c|c|}
\hline Enzyme activity measured & Control & DEHP-fed \\
\hline $\begin{array}{l}\text { - Pristanoyl-CoA oxidase }{ }^{a} \\
\text { - Palmitoyl-CoA oxidase } \\
\text { - } \text { Catalase }^{\mathrm{b}} \\
\text { - 3-Oxopalmitoyl-CoA thiolase } \\
\text { - 3-Oxopristanoyl-CoA thiolase }\end{array}$ & $\begin{array}{c}4.2 \pm 0.8(3) \\
48 \pm 4(4) \\
15.8 \pm 1.2(4) \\
604 \pm 120(3) \\
41 \pm 8.2(3)\end{array}$ & $\begin{array}{c}3.4 \pm 1.1(3) \\
206 \pm 45(4) \\
5.3 \pm 0.9(4) \\
5295 \pm 840(3) \\
10 \pm \quad 1.5(3)\end{array}$ \\
\hline
\end{tabular}

Results are in ${ }^{\mathrm{a}} \mathrm{nmol} / \mathrm{min} . \mathrm{mg}$ protein or ${ }^{\mathrm{b}} \mu \mathrm{mol} / \mathrm{min} . \mathrm{mg}$ protein and represent the mean \pm S.D. with the number of different preparations analyzed between parentheses.

high purity [28]. In accordance with literature data peroxisomes from peroxisome proliferator- treated rats have increased palmitoyl-CoA oxidase activity whereas the specific activity of catalase is lower in these peroxisomes (Table I).

When thiolase activities were measured in the two types of peroxisomes, different results were found depending upon the type of substrate used. Indeed, 3oxopalmitoyl-COA thiolase activity was found to be much higher in peroxisomes from DEHP-treated rats whereas with 3-oxopristanoyl-CoA as substrate a lower thiolase activity was found in peroxisomes from DE HP. fed rats (Table I).

The finding that DE HP-treatment had a differential effect on the 3-oxopalmitoyl-CoA and 3-oxopristanoylCoA thiolase activities in peroxisomes, strongly suggested that these two 3-oxoacyl-CoA esters are not handled by a single thiolase. The data on the effect of DEHP on the 3-oxopristanoyl-CoA thiolase activity in peroxisomes implies that 3-oxopristanoyl-CoA might be a poor substrate for the peroxisome proliferator-inducible peroxisomal thiolase identified by Hashimoto and coworkers [25]. In order to investigate this we purified rat-liver peroxisomal thiolase from clofibrate-induced rat livers using published procedures [25] and tested its reactivity with 3-oxopal mitoyl-CoA and 3-oxopristanoyl-CoA. These experiments performed in the presence and absence of BSA $(4 \mu \mathrm{M})$ revealed that this thiolase shows virtually no activity with 3-oxopristanoyl-CoA (Fig.1). The results show that BSA does not only have an effect on the apparent affinities but also eliminates the substrate inhibition found at higher substrate concentrations.

The results obtained raised the question which peroxisomal thiolase would be responsible for the thiolytic cleavage of 3-oxopristanoyl-CoA. The recently identified SCP $x$ with sterol carrier protein and thiolase activity [24] is a likely candidate especially since it is known that peroxisome proliferators have no effect on SCP2/ SCPX mRNA and protein levels [31]. The results of Fig.2 show that SCPx is not only reactive with 3-oxopalmitoyl-CoA in line with data described before [24] but also with 3-oxopristanoyl-CoA. The results further show that SCPx has high affinity for both types of 3oxoacyl-CoA esters especially in the absence of BSA. Clearly, SCPx showed highest activity with 3-oxopristanoyl-CoA.

\section{DISCUSSION}

The 56 kDa SCPx, alternatively called SCP2/3-oxoacyl-COA thiolase [24], and SCP 2 are produced from different mRNAs derived from a single gene having two promoters. SCP2 has been implicated in the intracellular trafficking of a variety of lipids which conclusion is largely based on in vitro experiments, however.

The function of the $56 \mathrm{kDa}$ SCPx with 3-oxoacyl-CoA thiolase activity and intrinsic sterol carrier protein ac-

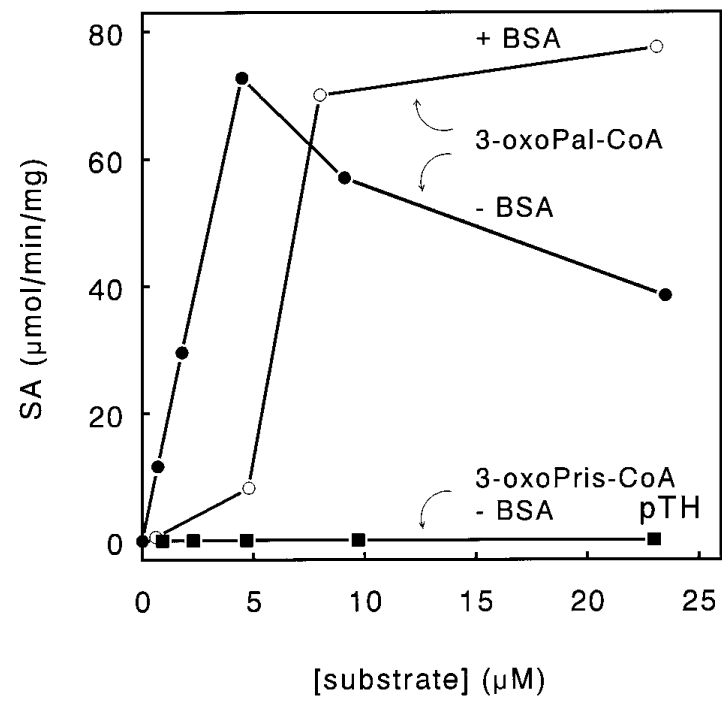

FIG. 1. Reactivity of the conventional peroxisome proliferatorinducible peroxisomal thiolase with 3-oxopalmitoyl-CoA and 3-oxopristanoyl-CoA. Peroxisomal thiolase was purified from rat livers taken from rats fed $2 \%(\mathrm{w} / \mathrm{v})$ di-(2-ethylhexyl) phthalate according to Hashimoto and coworkers [25]and thiol ase activity measurements were performed as described in Materials and Methods using 3-oxopalmitoyl-CoA $(O, \bullet)$ and 3-oxopristanoyl-CoA (ם) as substrates at the concentrations as indicated in the Figure. $\bullet, \mathbf{\square}=$ minus BSA $(4 \mu \mathrm{M}) ; \bigcirc=$ plus BSA $(4 \mu \mathrm{M})$. 


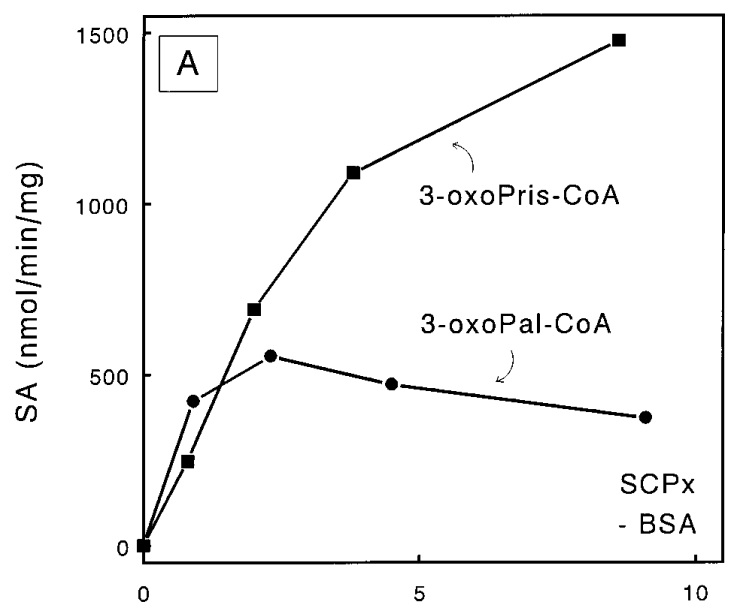

[substrate] $(\mu \mathrm{M})$

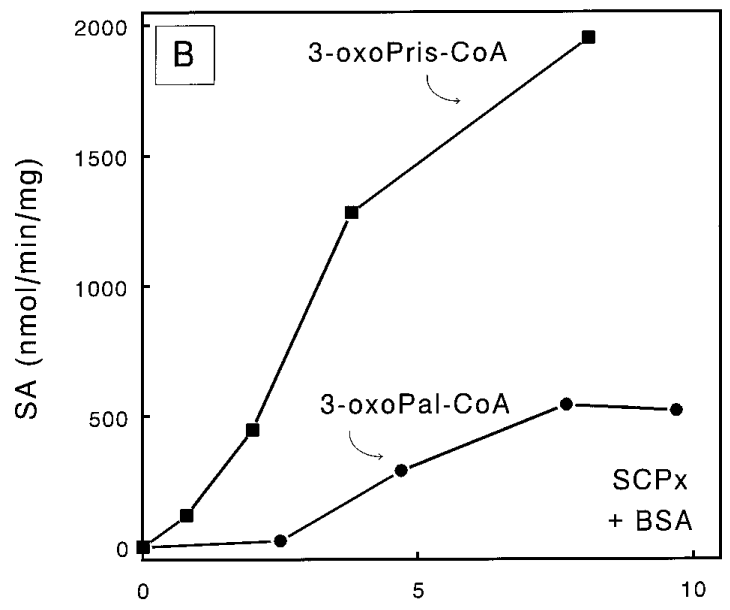

[substrate] $(\mu \mathrm{M})$

FIG. 2. Reactivity of rat liver SCPx (SCP2/3-oxoacyl-CoA thiolase) with 3-oxopalmitoyl-CoA and 3-oxopristanoyl-CoA. Rat liver SCPx was prepared by expressing the full-length CDNA coding for the entire SCPx (547 amino acids) in E.Coli followed by purification of the protein as described before [24]. Thiolase activity measurements were performed as described in Materials and Methods using 3-oxo-

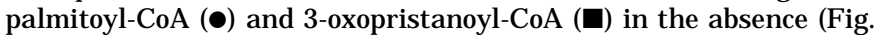
2A) or presence (Fig. 2B) of $4 \mu \mathrm{M}$ BSA.

tivity remained obscure especially since its substrate specificity was found to correspond closely with that of the conventional peroxisomal thiolase identified by Hashimoto and coworkers [25]. The results described in this paper indicate that SCPx fulfils a unique role in peroxisomal fatty acid oxidation catalyzing the thioIytic cleavage of the 3-oxoacyl-CoA ester of pristanic acid, a 2-methyl branched-chain fatty acid. The lack of activity of the conventional peroxisomal thiolase [25] with 3-oxopristanoyl-CoA suggests that SCPx is essential for the $\beta$-oxidation of pristanic acid and possibly other 2-methyl branched-chain fatty acids. In this respect it is important to mention di- and trihydroxy- cholestanoic acid which also possess a methyl-group at the 2-position. Both cholestanoic acids are produced from cholesterol, undergo activation to their CoA-esters and are then $\beta$-oxidized in peroxisomes with the COAesters of chenodeoxycholate and cholate as endproducts, respectively [26]. Preliminary studies show that the 3-oxoacyl-CoA esters of these cholestanoic acids are also handled exclusively by SCPx and are not accepted as substrate by the conventional thiolase.

Recent studies from different laboratories [32-35] have led to the identification of a new peroxisomal Multifunctional $\beta$-Oxidation Protein (pMOP2) in peroxisomes with 3 functional units including enoyl-CoA hydratase activity, 3-hydroxyacyl-CoA dehydrogenase and remarkably, sterol carrier protein activity. This enzyme was first discovered by Adamski and coworkers [36] as a distinct $17 \beta$-hydroxysteroid dehydrogenase. Convincing evidence has been brought forward suggesting that this enzyme (pMOP2) and not the long-

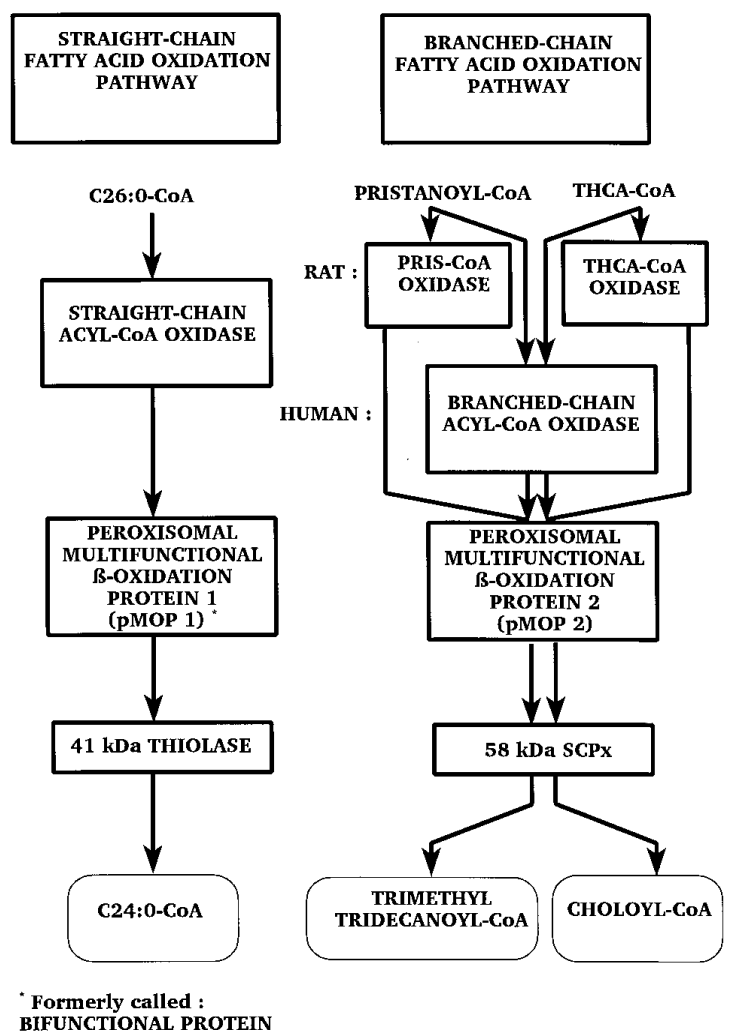

FIG. 3. Proposed structure of the peroxisomal fatty acid $\beta$-oxidation machinery. Based on the results described in this paper and data in literature we propose separate systems for the oxidation of straight-chain and branched-chain fatty acids. Abbreviations used: PRIS-COA oxidase = pristanoyl-COA oxidase; THCA-COA = trihydroxycholestanoyl-CoA; pMOP1 = peroxisomal multifunctional $\beta$-oxidation protein 1, also called bifunctional protein (see [37]); pMOP2 $=$ peroxisomal multifunctional $\beta$-oxidation protein 2 , also known as: $17 \beta$-hydroxysteroid dehydrogenase IV [32], multifunctional protein 2 (MFP2) [33], peroxisomal multifunctional enzyme II (per MFE-II) [34]) and D-specific bifunctional protein [35]. 
known bifunctional protein with hydratase and 3-hydroxyacyl-CoA dehydrogenase activity [37] (here named: pMOP1) catalyzes the hydration and subsequent dehydrogenation of the enoyl-CoA esters of 2methyl branched-chain fatty acids such as pristanic acid [34] and trihydroxycholestanoic acid [33]. Earlier studies had already shown the existence of separate oxidases for straight-chain and branched-chain acylCoA esters (see [26] for details). Taken together, these data suggest the existence of two distinct pathways in peroxisomes for straight-chain and 2-methyl branchedchain fatty acids as depicted schematically in Fig. 3.

The finding that SCPX plays a unique role in 2methyl branched-chain fatty acid oxidation in peroxisomes, will also have implications for human diseases. I ndeed, a great number of patients has been identified with an unknown defect in peroxisomal $\beta$-oxidation. These patients almost invariably show a range of fatty acid abnormalities in plasma including elevated pristanic acid and di- and trihydroxycholestanoic acid levels (see [38] for details), which results from some defect in peroxisomal $\beta$-oxidation. Our results suggest that SCPx deficiency may well be one of the underlying defects in these patients. Such studies are underway.

\section{REFERENCES}

1. Wirtz, K. W. A. (1991) Annu. Rev. Biochem. 60, 73- 99.

2. Chanderbhan, R., Noland, B.J., Scallen, T.J., and Vahouny, G. V. (1982) J . Biol. Chem. 257, 8928- 8934.

3. Vahouny, G. V., Chanderbhan, R., Fisku, G., Noland, B. J ., and Scallen, T. J . (1984) Biochem. Biophys. Res. Commun. 122, 509515.

4. Vahouny, G. V., Chanderbhan, R., Noland, B. J ., Irwin, D., Dennis, P., Lambeth, J. D., and Scallen, T. J . (1983) J . Biol. Chem. 258, 11731- 11737 .

5. Chanderbhan, R., Tanaka, T., Strauss, J . F., Irwin, D., Noland, B. J ., Scallen, T. J ., and Vahuny, G. V. (1983) Biochem. Biophys. Res. Commun. 117, 702- 709.

6. Trzeciak, W. H., Simpson, E. R., Scallen, T.J ., Vahouny, G. V., and Waterman, M. R. (1987) J . Biol. Chem. 262, 3713- 1717.

7. Fujiki, Y., Tsuneoka, M., and Tashiro, Y. (1989) J . Biochem. 106, 1126- 1131

8. Ossendorp, B. C., van Heusden, G. P. H., and Wirtz, K. W. A. (1990) Biochem. Biophys. Res. Commun. 168, 631- 636.

9. Billheimer, J . T., Strehl, L. L., Davis, G. L., Strauss, J . F., III, and Davis, L. G. (1990) DNA Cell Biol. 9, 154- 163.

10. Seedorf, U., and Assmann, G. (1991) J . Biol. Chem. 266, 630636.

11. Mori, T., Tsukamoto, T., Mori, H., Tashiro, Y., and Fujiki, Y. (1990) Proc. Natl. Acad. Sci. USA 88, 4338-4342.

12. Moncecchi, D., Pastuszyn, A., and Scallen, I. J . (1991) J . Biol. Chem. 266, 9885- 9892.

13. Yamamoto, R., Kallen, C. B., Babalola, G. O., Rennert, H., Bil- leheimer, J . T., and Strauss, J . F., III (1991) Proc. Natl. Acad. Sci. USA 88, 463- 467.

14. van den Krift, T.P., Leunissen, J ., Teerlink, T., van Heusden, G. P. H., Verkley, A. J ., and Wirtz, K. W. A. (1985) Biochim. Biophys. Acta 812, 387- 392.

15. Tsuneoka, M., Yamamoto, A., Fujiki, Y., and Tashiro, Y. (1988) J. Biochem. 104, 560-564.

16. Keller, G-A., Scallen, T.J ., Clarke, D., Maher, P. A., Krisans, S. K., and Singer, S. J . (1989) J . Cell Biol. 108, 1353- 1361.

17. van Amerongen, A., van Noort, M., van Beckhoven, J . R. C. M., Rommerts, F. F. G., Orly, J ., and Wirtz, K. W. A. (1989) Biochim. Biophys. Acta 1001, 243-248.

18. Ossendorp, B. C., van Heusden, G. P. H., de Beer, A. L. J ., Bos, K., Schouten, G. L., and Wirtz, K. W. A. (1991) Eur. J . Biochem. 201, 233- 239.

19. He, Z., Yamamoto, R., Furth, E. E., Schantz, L. J ., Naylor, S. L., George, H., Billheimer, J . T., and Strauss, J . F., III (1991) DNA Cell Biol. 10, 559-569.

20. Seedorf, U., Raabe, M., and Assmann, G. (1993) Gene (Amst.) 123, 165- 172.

21. Ohba, T., Rennert, H., Pfeifer, S. M., He, Z., Yamamoto, R., Holt, J . A., Billheimer, J. T., and Strauss, J. F., III (1994) Genomics, 24, 370- 374.

22. Ohba, T., Holt, J. A., Billheimer, J .T., and Strauss, J.F., III (1995) Biochemistry 34, 10660- 10668.

23. Baker, M. E., Billheimer, J . T., and Strauss, J . F., III (1991) DNA Cell Biol. 10, 695-698.

24. Seedorf, U., Brysch, P., Engel, T., Schrage, K., and Assmann, G. (1994) J . Biol. Chem. 269, 21277-21283.

25. Miyazawa, S., Furuta, S., Osumi, T., Hashimoto, T., and Ui, N. (1981) J . Biochem. 90, 511-519.

26. Reddy, J. K., and Mannaerts, G. P. (1994) Ann. Rev. Nutr. 14, 343- 370.

27. Van Roermund, C.W.T., Van den Berg, M., and Wanders, R. J . A. (1995) Biochim. Biophys. Acta 1245, 348- 358.

28. Wanders, R. J . A., Romeyn, S. J ., Schutgens, R. B. H., and Tager, J . M. (1989) Biochem. Biophys. Res. Commun. 164, 550- 555.

29. Wanders, R.J . A., Denis, S., J akobs, C., and Ten Brink, H.J. (1992) Biochim. Biophys. Acta 1124, 199- 202.

30. Rasmussen, J. T., Borcher, T., and Knutsen, J . (1990) Biochem. J . 265, 849-855.

31. Matsuo, R., and Strauss, J . F., III (1994) Endocrinology 135, $1135-1145$.

32. Leenders, F., Tesdorpf, J . G., Markus, M., Engel, T., Seedorf, U., and Adamski, J . (1996) J . Biol. Chem. 271, 5438- 5442.

33. Dienaide-Noubhani, M., Novikow, D., Baumgart, E., Vanhooren, J . C. T., Fransen, M., Goethals, M., Van de Kerckhove, J., Van Veldhoven, P. P., and Mannaerts, G. P. (1996) 240, 660- 666.

34. Qin, Y-M., Pontanen, M. H., Helander, H. M., Kvist, A-P., Siivari, K.M., Schmitz, W., Conzelmann, E., Hellmann, U., and Hiltunen, J . K. (1997) Biochem. J . 321, 21- 28.

35. J iang, L. L., Kobayaski, A., Matsuura, H., Fukushima, H., and Hashimoto, T. (1996) J . Biochem. 120, 624-641.

36. Adamski, J ., Husen, J ., Marks, F., and J ungblut, P. W. (1992) Biochem. J . 288, 375- 381.

37. Osumi, T., and Hashimoto, T. (1980) J . Biochem. 87, 1735- 1746.

38. Wanders, R. J . A., Schutgens, R. B. H., and Barth, P. G. (1995) J . Neuropathol. Exp. Neurol. 54, 726- 739. 